\title{
PSYCHODYNAMIC ASPECTS OF THE PROBLEM OF DEFINITION OF OBSCENITY
}

\author{
D. W. ArsE*
}

I

The exaggerations manifested in disease sometimes throw into bold relief processes which are present, though muted, in everyday living. Faced as he often is by pathological distortion, a psychiatrist, on the basis of this special experience, may sometimes point up the presence of events otherwise unnoticed in the commonplace. Nonetheless, despite the bolstering effect of these reflections, the ancient admonition to the cobbler to stick to his last suggests caution in this task of seeking some limits to the definition of obscenity. We can do no more than point up the possibility of the application of certain concepts useful in the study of psychopathological processes.

We begin then with our own habitual point of vantage-though others may describe it as a worm's eye view-and aloft and winged and eagle-eyed stare disdainfully. It is literally and etymologically obvious that the word "obscenity" refers to what is repulsively filthy. We will first briefly consider some pathological conditions in which obscenity often figures.

Often, a patient suffering from a severe schizophrenic psychosis will evince behavior commonly dubbed obscene. For example, he may smear the walls of his room with his feces. Or he may so smear his therapist. From such a patient, we may come to understand that he is enjoying himself, expressing defiance. Neither enjoyment nor defiance, however, are in themselves obscene; Grenville, keeping the guns of "The Revenge" blazing against several vessels of the King of Spain's Armada despite fearsome odds, strikes one as a heroic figure. Thus, it is immediately noticeable that obscenity, like beauty, is also in the eye of the beholder. When we come to know more about the so-called obscene behavior of the schizophrenic mentioned above, we may find that he, like Grenville, feels himself to be cut off from all support and surrounded by threatening enemies. It is rather the archaic modality of his expression and gratification which makes it repulsive and filthy to the observer and, in one part of his mind, to the agent too. In general, we find that the

* B.Sc. 1935, University of Wales; M.B. and B.Ch. 1938, Welsh National School of Medicinc; D.P.M. I940, University of London; M.D. 1948, University of Wales. Associate Professor of Psychiatry, School of Medicine, University of North Carolina. Specialist in Psychological Medicine, Royal Army Medical Corps, r942-r947; Deputy Medical Superintendent, Monmouthshirc Mental Hospital, United Kingdom, 1947-48; in private psychiatric practice in London with appointment at Charing Cross Hospital, 1948-5I; Clinical Director, State Hospital, Raleigh, N. C., 195I-53. Author, The Diagnosis of Hysteria (1950); Modern Treatment of Depression, in Medical TreatMent Yearbook (Cecil Wakelcy ed. 1950); The Psychologic Implications of Shock Therapy, I 66 INT'L RECORD OF MEDicine AND GENERAL. Practice Clinics 287 (I953). 
schizophrenic is withdrawn from outer adult reality and expresses himself in language and action patterns that are partly decipherable as that appropriate to the nursery. We use the term "regression" to sum up this state of affairs-that the patient, in his behavior, goes back to patterns appropriate to an earlier age, perhaps to infancy. ${ }^{1}$

There is another aspect of the matter perhaps best pointed up by reference to another pathological condition in which obscenity often figures. In organic disorganization of the central nervous system, as occurs temporarily, for example, in alcoholic intoxication, various deficiencies of mental functioning are manifest. Studies of the physiology and pathophysiology of the brain have led us to account for some of these deficiencies on the basis of disinhibition or "release." In other words, the inhibitory forces usually in operation are damaged, with consequent release of forces which otherwise would not achieve expression. Such "release phenomena" sometimes include obscene words and behavior alien to the behavior of the same person when sober. ${ }^{2}$

It happens, in general, in both organic and functional nervous disease, that release and regressive processes occur concomitantly and are, in fact, but two of several aspects of the same total process of increasing disintegration of adult personality function. Some of the manifestations of release and regression are regarded by the observer-and possibly, in areas of more mature function, sequestrated in the mind of the agent-as repulsive and filthy.

We have now to address ourselves to the question of why this reaction should

${ }^{2}$ Some schizophrenic symptoms are direct expressions of regressive breakdown of the ego and an undoing of differentiations acquired during mental development. Other symptoms, however, are more cxpressive of attempts at restitution. An early discussion in terms of regressive and rcstitutive processes is contained in C. G. Jung, Psychology of Dexientia Praecox (I909).

${ }^{2}$ In the Igth century, Hughlings Jackson came to distinguish levels in the general distribution of function in the central nervous system. His work showed three principal levels: that of the spinal cord, that of medulla and mid-brain, and that of the cerebral cortex. He found that the spinal cord, even when cut off from higher levels, effects some degree of integration of sense organs and muscles below the neck; that at the intermediate level, integration of primitive orientation to gravity, light, and sound occurs; whereas the cerebral cortex is the center for voluntary and intelligent activity. This concept of levels acquired additional importance in neurology and neurophysiology, especially through the work of Sir Charles Sherrington. Sherrington, in his book, The Integrative Action of the Nervous System (1906), describes, in particular, experiments to show that the higher centers normally exercise an inhibiting effect upon the function of the lower centers, and that exaggerated behavior having its origins in specific functions of lower centers becomes apparent when the higher centers fail to exercise controlso-called "release phenomena." The concepts of levels and of inhibition and release have been extensively elaborated in later neurophysiological research. In his textbook, Diseases of the Nervous System 7 (4th ed. I95I), Sir W. Russell Brain writes: "We must first consider a conception which we owe to Hughlings Jackson and which is of great importance in the interpretation of nervous symptoms, namely, the distinction between the positive and negative elements in nervous symptomatology. Following a capsular haemorrhage, we find a loss or impairment of certain functions, e.g., voluntary movement. The functions lost, or the negative elements, were clearly dependent upon the integrity of the structures destroyed, i.e., the pyramidal tract. We also observe new phenomena which were not present before the lesion, e.g., muscular hypertonia and an extensor plantar reflex. These, the positive elements, cannot be the direct result of a destructive lesion, but must be manifestations of the activity of other intact parts of the nervous system which have been released or escaped from control as a result of the damage to the fibres destroyed. If this distinction is borne in mind it will greatly clarify neurological symptomatology." 
be so emotionally toned. Early in life, the child learns to interpret the responses of parents or of nursing attendants as signifying pleasure or annoyance with him. This approval or disapproval, the critical attitude of mother, father, or nurse, later becomes incorporated into the self as self-observation and self-criticism. Freud gave the name "superego" to this inspecting agency within the mind, ready to criticize, forbid, and punish on the one hand-as were the persons to whom the infant first related himself-and ready to approve, console, and forgive on the other hand-again, much as occurred in early actual experience with others. ${ }^{3}$ The matter is, however, complicated by exuberant phantasy in childhood which colors the character of the superego beyond the actual facts of experience. And it needs to be stressed, too, that just as much early experience and phantasy is forgottenthat is, repressed or excluded from consciousness--so is the superego, one instance of the outcome of this experience, largely unconscious. It is what remains of superego functions which, as it were, cries out "horrible" in the mind of the agent of obscenity and produces the feeling of disgust.

In alcoholic intoxication, for example, a person may say and do much that he cannot later recall, but he may, nonetheless, experience considerable remorse. "Conscious conscience" may, indeed, have been dissolved in the alcohol; yet, much was noted unconsciously; and "the wages of sin" need to be paid up in full later. Nay, only too often the price is much more severe, in terms of remorse, than conscious appraisal of all the acting and talking out under the influence of alcohol would suggest. For the larger part of the superego is very remote from adult reality, grounded, as it is, in repressed infantile experience and phantasy.

Psychoanalytic study of repressed instinctual impulses, affects, and phantasies led Freud to the discovery that during infancy and early childhood, a rapid development of sexual instincts takes place. ${ }^{4}$ Previously, it had been thought that sexuality

${ }^{3}$ In The Ego and the Io (4th ed. 1947), Sigmund Freud showed that the instinctual attitudes of the children towards their parents are turned into forces hostile to the instincts by an introjection of the parents. The anti-instinct forces have an instinctual character because they are derivatives of instincts; thus, they may be frequently stormy and emotional. Freud writes: "The broad general outcome of the sexual phase governed by the oedipus complex may, therefore, be taken to be the forming of a precipitate in the ego. ... This modification of the ego retains its special position; it stands in contrast to the other constituents of the ego in the form of an ego-ideal or super-ego." Id. at 44. A vivid account of the process of development of the superego is contained in Susan Isacs, Soctal Development IN Young ChILdren 366-75 (1933). There are numerous discussions of this topic in psychoanalytical litcrature, including Ernest Jones's paper, The Origin and Structurc of the Super-Ego, 7 INT'L J. PsrchoANALYSIS 303 (1926).

"In Three Contributions to the Theory of Sex 35-64 (4th ed. 1930), Sigmund Freud showed that the instinctual nature of the small child comprised an undifferentiated sexuality in which the genitals play the part of primus inter pares among many erogenous zones and have not yet assumed dominance. The development from early pregenital strivings to genital primacy is described in two ways: there is change in leading crogenous zones and change in types of object-relationship. In many papers, Freud has shown the etiological importance of disturbances in this early psychosexual development for sub. sequent adult neurosis. Thus, for example, may be listed: My Views on the Part Played by Sexuality in the Etiology of the Neturoses, in I Collected PAPERs 272 (4th ed. 1948); The Predisposition to Obsessional Neturosis, in 2 Collected PAPERs 122 (5th ed. 1948). A brief account of psychoanalysis, giving a clear exposition of the phases of mental development, is EDWArD Glover, Psycho-ANalysis, A Handbook for Medical Practitioners and Students of Comparative Psychology (2d ed. 1949 ). 
originated at puberty. ${ }^{5}$ This view was corrected by psychoanalytic study in the treatment process, and Freud found that sexuality could be traced back to infancy and comprised loosely organized component instincts, only later organizing under the primacy of genitality. A number of primitive components, derived from several erotogenic body zones, were traced-oral, anal, cutaneous, muscular, and phallic. These infantile components of sexuality were fused with aggressive and destructive instincts in various degrees, and this infantile sadism, fused with sexual strivings, was focused in the direction of the parents. Between the third and fifth year of life, these sexual sadistic strivings came under the primacy of infantile genital zones, giving rise to the famous so-called "Oedipus" phase of development, with prominent sexual rivalry, feelings of guilt, and fear of punishment. Because of the need to be loved and the fear of punishment, repression of the forbidden sexual strivings and phantasies ensued, which resulted in a massive amnesia for these events which could only be penetrated by special techniques of study.

As previously stated above, early in life, the child learns to interpret the responses of parents as signifying pleasure or anger with him. This approval or disapproval becomes incorporated into the self as the superego function; this later, internally, is responsible for the activation of repression of forbidden wishes on the model of the repression of the Oedipus complex of incestuous and sadistic strivings and phantasies.

The psychological facts adumbrated above may enable consideration of both a clinical example of obscene conduct disorder and the unconscious motivation and conflict with conscience involved.

During the early part of World War II, a soldier was referred for psychiatric examination because he had, at machine gun practice, shown generalized tremors and obvious fear. Since he had often previously attended such practice and shown himself effective, there was some surprise when he suddenly became panic-stricken on this occasion. In psychiatric interview, the soldier explained that he was not at all frightened by the gunning to which he had long since become accustomed. Questioning showed, however, that he had become very worried shortly before this incident, but he was reticent about his worries. Finally, in the first interview, he spoke about his feelings on being separated from his wife, who remained on the small farm in Ireland whence he came. He explained that he had traveled to England to enlist in the British army because times were bad on the farm, and that in this way, he could send his wife and children a good allowance which would supplement the meagre living they eked out on the small holding. He was encouraged to talk about his background and gave a good account of himself. $\mathrm{He}$ had lost his father at an early age and, as the youngest son, had remained on the small farm with his widowed mother, supporting her by his hard work until her

\footnotetext{
'A. Moll, in his book, Das Sexual-leben des Kindes (1909), admits only that sexual manifestations appearing after the age of eight are not pathological; and his work is the first to acknowledge sexual manifestations in children as otherwise than pathological when occurring before puberty.
} 
death in old age. Later, he had married, but the farm had not been sufficient to support his growing family; and he saw his chance, with the outbreak of war, to fulfil his obligations as a father and husband more adequately. He was now looking forward to a period of leave so that he could temporarily be with his family again. He agreed that it was just at this time that he started to feel apprehensive and to suffer from disturbed sleep with the ensuing episode at gunnery practice, but no more was elicited at this time.

In the next interview, the soldier appeared very anxious and stated he had a lot on his mind that he had not told, and went on to speak of his terrible habit. Away from his wife so long he had felt the need of sexual intercourse, and, when off-duty, he had wandered around the fields until he came across a piggery. He had repeatedly had sexual connection with a sow. He had felt badly about this, for this habit, which he had given up before marriage, had already caused him much inward painful feeling. He had requested to see the local priest, and when he saw this individual, he was dismayed to see a young man. However, he had confessed to him, just as in the old days he had to the father in the nearby village. This young priest was, so the soldier felt, horror-stricken and had told him that he could not be received into the church until such time as he ceased from this horrible habit. After this, he had felt worse and was sure that some terrible accident would occur at gun practice and kill him before he had a chance to see his family again. In the course of further psychotherapy, the soldier spoke of his lonely childhood on the remote farm. Shortly after he had started masturbating in puberty, incestuous thoughts about his mother had occurred to him which made him feel badly. He had much contact with pigs and knew how to handle them by massaging them to make them quite docile. In this way, he had learned to make a sow receptive and had developed what we might shortly term a sexual pig-fixation. After some time, worried greatly about this, without informing anyone else, he had confessed to the old priest, who had taken a very different attitude from the young one in England. For after confessing to him, he had always felt forgiven, as he was truly repentent, and it was some time before he had had a pig-relapse again. Gradually, the relapses had become less and less frequent under the influence of his intermittent confessions to the priest. After his mother had died, following the priest's advice, he had married and experienced no further trouble until separated from his wife and in the army.

Subsequent exploration in this case of bestiality revealed that unconsciously the patient had equated the sow and his obese and food-addicted mother, who had, in fact, been a very demanding personality. He had been enraged at the demands his mother put upon him and had, at the same time, felt very guilty about his hostile feelings. All the more did he feel it necessary to work hard and feed his mother, a motive that characteristically had persisted in his feeling of responsibility towards his growing family. The old symbolic rebellious acting out had revived with its 
incestuous-sadistic connections in unconscious phantasy and with the self-punishment in humiliation and mental pain that it involved.

There is no need here to pursue further the genetics and dynamics of this case of sexual perversion. So far as this has been discussed, however, we can use this as a pathological model at the extreme end of the spectrum of obscenity for the glaring light it throws on the psychological implications of obscenity generally. It demonstrates the release of repressed unconscious rebellion in regressively acting out infantile sexual and sadistic ("polymorph perverse") incestuous phantasies. And it demonstrates, too, the guilt and shame reactions to this release.

\section{II}

Clinical experience shows that when, in infancy and childhood, the individual has had the opportunity to grow through, more or less adequately, pregenital strivings and phantasies in a parental atmosphere of love and tolerance, subsequent adult interest in release in obscenity is considerably diminished, and subsequent disgust is likewise less intensive. There is always a balance, during growth, of gratification and frustration, and the optimal atmosphere for emotional development consists in the most favorable balance to support the particular child's needs and, at the same time, to stimulate growth. Overindulgence can cause fixation in an infantile psychosexual phase, just as undue deprivation can. Where such fixation has occurred, the possibility of regression to it is readily aroused, and this is likely to occur especially when frustration of more evolved strivings occurs as a result of unfavorable circumstances in life. ${ }^{\circ}$ When regression is activated by frustration, the individual may defend himself unconsciously against the expression of the wishes and phantasies connected with the particular immature phase of fixation. These may, for example, remain completely repressed, but there are other possibilities: they may obtain access to consciousness so transformed that they are ego-syntonic and socially acceptable; or they may attain expression insufficiently transformed so that conflict becomes manifest, as in the clinical example detailed above. Of course, in life, the ideal of optimal development is more or less approached, and this development depends on constitutional as well as environmental factors. Modern psychiatric investigative techniques largely confirm the important role of the early personal environment, which, before Freud, was so hidden from view that overmuch emphasis was placed on either constitutional or later educational influences. These latter are important operative factors, but the early transactions within the parentalinfant relationship are now also accorded considerable significance for the later fate of the personality.

As a general statement, the more there is fixation in immaturity, the more there is repression and the less there may be of sublimation or other acceptable transformations of pregenital longings. In life, consequently, masses of human beings are delighted when opportunity is afforded for release of anachronistic impulses, phan-

\footnotetext{
- A general account of the personality defences utilized to protect against mental pain is afforded by Anna Freud, The Ego and the Mechanisms of Defence (1937).
} 
tasies, and wishes in a form which, too, is more or less archaic. For many people, however, that this delight may be secured, conditions are necessary to obviate guilt and shame. Otherwise, the excitation of delight is overshadowed by the excitation of guilt and shame; and before this becomes fully developed, a feeling of disgust is manifest. When we feel something to be ordure and repulsive or disgusting, this is a signal which protects us from further involvement in guilt and shame and cognate painful feeling. In fact, many people cannot endure release of repressed infantile strivings unless these are much transformed or else certain conditions prevail -for under the spell of certain conditions, detoxication without full transformation becomes possible. It is when there is inadequate transformation, and these conditions are not met, that expression of infantile strivings is adjudicated objectionable and obscene.

Before closing into the area of the "obscene" in order to scrutinize the question of what is inadequate transformation without adequate detoxication, we need to clarify some further concepts.

One sort of adequate transformation already mentioned is sublimation. An example of this is that early forbidden sexual curiosity may be transformed into laudable scientific investigation. For our purpose here, we will consider the study of anatomy briefly. Even in the eighteenth century, Linnaeus, in his great work, The System of Nature, discussed as "abominable" the exact study of the female genitals, although he admitted the scientific interest of such investigations. ${ }^{7}$ It is true that R. de Graef accomplished this purpose a century earlier in his famous treatise on the generative organs of women, but he considered it necessary to apologize for the subject of his work in the preface. ${ }^{8}$ About the same time too, Rolfincius, in his work devoted to the sexual organs of women, cited what ancient writers had said of Elusinian and other mysteries-that these sacred rites required a dedicated approach in a spirit of devotion and purity. "It is also so with us," he wrote, "in the rites of scientific investigations; we also operate with sacred things. The organs of sex are to be held among sacred things. They who approach these altars must come with devout minds. Let the profane stand without, and the doors be closed."

In the case of anatomy, the transformation is no longer remote from the original source of interest in the human body, as it is, for example, in the study of archaeology, so that the scientists displayed some evident difficulty. The conditions they required to establish in order to get over the feeling of "abominable" in themselves or others may be shortly described as congruent with prevailing adult standards. Today, there is no need for explicit statement, but congruity with adult standards is implicitly maintained. These standards are based on scientific judgment values relating to the necessity to know the facts, the use which knowledge of the

${ }^{7}$ C. Linnaeus, Systema Naturae (I748).

${ }^{8}$ R. DeGraef, De Mulierum Organis Generatione Inservientibus (1672).

- Rolfincius, Ordo et Methodus Generationi Partium (i664). 
facts may have for human betterment or purpose, and so forth. Such judgment values may delete effectively any compunction.

In the process of such deletion, medical students may evince disgust or other similar disturbance but feel that, despite such feelings, persistènce is required. In particular cases, access to the underlying sexual-sadistic phantasies has been possible and requisite, and these have been noted as the cause of such disturbances. This exemplifies that where transformation is inadequate, conditions are required which reflect judgment values acquired in the process of later education.

It may not be inappropriate to single out another example here. Interest in the law may spring from the need to understand precisely how behavior is regulated in society. Sometimes, this may be the result of a transformation which we may briefly describe as a reaction-formation against unconscious rebellious instinctual strivings. These strivings may have aroused much anxiety in the individual. In such a case as this, it is the individual's inward defenses that are supplemented by his alertness to what actual regulations in society are mandatory. This is not merely a hypothetical case, but it would be mere casuistry to generalize too narrowly from this, for adult interest and choice of profession, in this as in other cases, is far more complex in its determination.

Here we need to understand, in some measure, the prevalent conditions of childrearing in western civilization. Toilet-training is generally insisted upon very early in life. The infant quickly gets to learn that making a mess is disapproved of. The novelist, Linklater, has wittily described the infant as a biological system of uncontrolled orifices. ${ }^{10}$ In our civilization, this state of affairs is generally strenuously corrected at a time when it presents a formidable task to the infant. In many instances, there is a complex struggle with varying results. The infant, in his need for love and security and fear of rejection, may quickly learn to please, and his resentment may be only very incompletely expressed. With such incomplete resolution of resentment and defiance, there results an unconscious legacy of fear of making a mess on the one hand, and a readiness to defy authority under certain conditions on the other. Thus, at first, the defiance may be partly expressed in the body-language of defecating and urinating inappropriately in time and space; later, verbally, in the form of excrementitious obscenity when frustrated. Of course, the child may get to be altogether on the side of the angels. In such an instance, however, later attitudes towards sexual expression are usually heavily colored by notions of dirtiness and messiness, and prurience may lurk ready for release. In general, in our society, the anal phase is inadequately worked through and comes to load character and attitudes towards sex and authority in multiform ways. It should also be emphasized that there are valuable contributions towards personality development accomplished during the anal phase, and that here we have been concerned only with common deficiencies due to faulty management early in life, especi-

\footnotetext{
${ }^{10}$ See Eric Linklater, Ripeness Is All 220-31 (1935).
} 
ally as these are related to the problem of the fascination with and the repulsion against the lewd. ${ }^{11}$

Freud has shown that wit can be utilized as a condition whereby forbidden sexual exhibition may obtain release without arousing disgust. ${ }^{12}$ In other words, obscenity may be transformed into so-called "obscene wit." This really means that it is no longer obscene in the sense of being repulsive. Wit makes possible the gratification of a lewd or hostile craving by eluding the hindrance of culture and education. Broad smut is enjoyed in vulgar circles, but the formal determination of wit arises among the refined and cultured. The obscenity becomes witty and is tolerated only if it is witty. Often, the technical means utilized by the wit in these instances is allusion-that is, substitution through a trifle, something remotely related, which the listener reconstructs in his imagination as a full-fledged obscenity. The greater the disproportion between what is directly offered, and what is aroused in the imagination of the listener, the finer is the witticism and the higher it may venture in society. Freud writes: ${ }^{13}$

The power which makes it difficult or impossible for the woman, and in a lesser degree for the man, to enjoy unveiled obscenities we call "repression," and we recognize in it the same psychic process which keeps from consciousness in severe nervous attacks, whole complexes of emotions, and which with their resultant effects has shown itself to be the principal factor in the causation of the so-called psychoneuroses. We acknowledge to culture and higher civilization an important influence in the development of repressions, and assume that under these conditions there has come about a change in our psychic organization which may also have been brought along as an inherited disposition. In consequence of it, what was once accepted as pleasureful is now counted unacceptable and is rejected by means of all the psychic forces. Owing to the repression brought about by civilization many primary pleasures are now disapproved by the censorship and lost. But the human psyche finds renunciation very difficult; hence we discover that tendency-wit furnishes us with a means to make the renunciation retrogressive and thus to regain what has been lost. When we laugh over a delicately obscene witticism, we laugh at the identical thing which causes laughter in the ill-bred man when he hears a coarse, obscene joke; in both cases the pleasure comes from the same source. The coarse, obscene joke, however, could not incite us to laughter, because it would cause us shame or would seem to us disgusting; we can only laugh when wit comes to our aid.

\section{III}

From the considerations already outlined, we may now approach the definition of the area of the obscene. This seems to coincide with the expression, verbally or non-verbally, of sadistic-sexual strivings associated with notions of dirt derived from preoccupation with excretory processes and emotionally toned with defiance

${ }^{11}$ A general discussion of anal-erotic character traits is contained in Ernest Jones's paper of this title, first published in $13 \mathrm{~J}$. Abnormal Psychology 26I (1918), and included in his Papers on Prsclio. Analysis 413 (5th ed. 1950). A more recent paper, entitled The Child's Response to Coercile Bowel Training, by Mabel Huschka, is published in Contemporary Psychopatholocy 36 (Tomkins ed. 1947).

${ }^{12}$ See generally, Sigmund Freud, Wit and Its Relation to the Unconsciots, in THE Basic Writings of Sigmund FREUd (Modern Library ed. 1938).

${ }^{13}$ FreUd, op. cit. sitpra note 12, at 696-97. 
of established authority. Transformation of sexual-sadistic content may sufficiently operate to take expression out of the realm of the obscene; or else conditions may obtain which detoxicate content without full transformation, as when wit comes to our aid. However, the whole range of art may be employed in such transformation or conditioning, as in poetry, music, painting, and sculpture, just as we have already noted that scientific investigation is able to lend its sanction.

We have to make clear, too, that transformation and conditioning may seem completely adequate, and yet objection may be raised by many on the basis of mis. interpretation. This misinterpretation may be unconsciously determined by unresolved infantile complexes in the minds of those who feel disgusted. It is evident that when we are confronted with a social transaction, we cannot confine our attention to the agent or producer, or to his production, or to his audience, but need to comprehend the total situation.

As an example, let us consider the situation with which Havelock Ellis was faced in 1898 in England. His publisher was accused ${ }^{14}$

... of having unlawfully and wickedly published and sold ... a wicked, bawdy, and scandalous, and obscene book called "Studies in the Psychology of Sex" ... [intending] to vitiate and corrupt the morals of the liege subjects of our Lady the Queen, to debauch and poison the minds of divers of the liege subjects of our said Lady the Queen, and to raise and create in them lustful desires, and to bring the liege subjects into a state of wickedness, lewdness and debauchery.

It is, of course, well known that Havelock Ellis' pioneering attempts to investigate the natural facts of sex have operated in the direction of more honesty and less hypocrisy, and we would not construe this as "corruption." As for the "creation of lustful desires," this was far from his intention, which was, on the contrary, to promote knowledge without which discipline in this area is all the more difficult. Ellis was evidently faced with a considerable difficulty, and this was the mind of Sir Charles Hall, the judge in this case, who described his studies as a "filthy work." 15

But we need, at last, to enter an even thornier thicket. There are, no doubt, many elements in the satisfaction we gain from works of art. ${ }^{16}$ Two of these may be identified as sensuous pleasure and the solution of emotional conflict. "Escape art" may almost exclusively devote itself to the former. The illusion may be pro-

14 I Havelock Elis, Studies in the Psychology of Sex xvii (Random House ed. 1936).

${ }^{15}$ Id. at xviii.

${ }^{10}$ Comparisons have been made of the spontaneous play of the imagination in works of art and in dreams. In particular, in varying degree, processes of condensation, displacement, and symbolization occur in both, whercas under other conditions of waking communication, the association of ideas is subject to stricter control. Part of the plcasurc involved in the satisfaction we gain from works of art is in this libcration from the stricter controls of the so-called "secondary process" and their partial replacement by primary processes, such as condensation and displacement. Sce discussion in CHARLEs Baudouin, Psychonalysis AND Aesthetics I5-34 (Eden and Cedar Paul transl. I924). This book is an early application of psychoanalysis to the theory of esthetics, as illustrated by a detailed study of Verhaeren's works. See also, Sigmund Freud, Formulations Regarding the Two Principles in Mental Functioning, in 4 Collected Papers r3 (4th ed. 1948). 
duced that anxiety and guilt or other painful feeling does not exist, that all is good and comfortable, and that wishes are realized magically. Beauty is thus depicted, and depending upon imaginative ideals, it has different emphases at different times and in different cultural contexts. Undoubtedly, this matter will be discussed in this symposium by the anthropologists and sociologists. Here I do not wish to entangle with those estheticians who attempt to show that the beautiful is identified with the Greek perfectionist ideal and is not a necessary condition of art. To my mind, this is mere chatter or play upon words; for the beautiful is not confined to such an ideal, but may be represented by others. An art product symbolically satisfies unconscious emotional needs. The symbol may be concretistic or abstract; in any event, it indirectly represents a fulfillment of strivings fashioned in experiences which date back to infancy. As far as the element of sensuous pleasure is concerned, different art forms may be capable of eliciting this in accordance with their power of indirectly representing conditions which, early in life, determined objectchoice. Plato's insistence that early education should consist in music and gymnastic, so that love of rhythm and harmony and grace of movement should result, was a development of this theme. Such a development gives sublimated form to pleasurable sensual infantile experience and enhances discriminative perceptual organization of the world on a sensual basis. Indeed, it was evidently Plato's opinion that, on this basis, one could educate towards good taste a very large number of people, whereas few were considered by the Philosopher as capable of being educated to think clearly. ${ }^{17}$

It is more relevant here to discuss the ugly-the frightful and hateful-of which obscenity is a sub-species, and in doing this, we shall find our way back to the element in art identified as the solution of emotional conflict. In accordance with an ideal of insistence upon objective reality, or truth, an artist may, in words or paint or otherwise, show something ugly; but by his adherence to his ideal as much as to the excellence of his techniques, his work may be transformed to a thing of beauty. This realism in art can lead to difficulties in categorization and accounts for a large number of perplexities. An extreme example may clarify this issue.

Anyone examining the series of etchings entitled "Les Misères et les Malheurs de la Guerre" by Jaques Callot (1633) may find himself, at first, both fascinated and horrified. Imperturbably, the artist depicts the events characteristic of the Thirty Years War. From etching to etching, pillage is followed by murder, murder by arson and rape, torture by execution. Callot's style conveys a strangulation of affect, an emotional neutralism, which all the more succeeds through its elegant precision in communicating the horrors of war. Incidentally, he depicts the marching off of nuns to be raped by the soldiery, a topic well within the confines of the "obscene." However, one feels sure that the intention of the artist is not to "create lustful desires," but, on the contrary, to raise a feeling of protest against the stupidities, (1937).

${ }^{17}$ Sec generally, Richard L. Nettzeship, Lectures on the Republic of Plato 77-130, 212-37 
follies, and cruelties which degrade mankind in the havoc of war. The unimpassioned and dry style engages all the more a feeling of protest in the observerof course, not necessarily so, for it is possible to conceive of one so sick upon whom the effect is otherwise.

This example may suffice to show that art may deal with the darker side, the cruel realities of life, just as entitled as science. The essential sanction for this, it seems to me, is the intention and its measure of success in evoking constructive feelings despite the destructive content. Indeed, the art consists in evoking constructive protest through its treatment of the destructive, so that we do not reject it in disgust, but feel inspired to feel we want to deal with it and get pleasure from this feeling.

Altogether, it is clear that, in this and other ways, ugliness can be transformed through esthetic expression.

In work of this nature, the artist faces anxiety and guilt and somehow masters pain. As Ernest Jones has shown, Shakespeare carries us in Hamlet into the conflictridden and painful Oedipus situation and depicts various aspects of its attempted solution. ${ }^{18}$ In this way, the artist does more than provide us with escape from our miseries; our reactions to them may be sufficiently disguised to obtain release, or else we may be inspired determinedly to master them.

There are various ways in which something can be in such a high degree displeasing that we are repelled and call it ugly. It may, for example, arouse phantasies of mutilation which are too overwhelming and cause too much anxiety and guilt. In a person in whom such phantasies, or cognate ones, are active unconsciously, they may find relief through disguised expression in art activity or appreciation which deals with these very phantasies adequately transformed. Where the transformation is inadequate for the particular person, repulsion is produced in him. On the other hand, the symbolic reference of the work of art to such phantasies may be so obscure to him that no appeal is made at all. In every case, there is a fine dynamic balance involved in the action of the particular art form upon the individual set to appreciate it. It is, indeed, partly because of this that the art of primitive tribes may be ugly to nationals of western civilization. Anxiety aroused by the relatively unconcealed sadistic phantasies may inhibit appreciation of the rhythm and harmony involved in the artist's treatment of the theme.

In the further light of this brief excursion into the larger realm of the ugly, the difficulties of precise defintion of obscene as applied to any product of the imagination of man become apparent. It is obvious that what is disgusting to one, may afford pleasurable release to another. Society has the task, nonetheless, of organizing nomothetic standards.

\footnotetext{
${ }^{20}$ See Ernest Jones, The Oedipus Complex as an Explanation of Hamlet's Mystery: A Study in Motive, 21 Am. J. Psychology 72 (1910), reprinted in Essays in Applied Psychoanalysis (1938).
} 
IV

In these days of narrow specialization, one may say even of cultural parochialism, it is unquestionably good to seek to reach beyond the limits of professional skills. The cobbler reluctantly departs from his last, nonetheless, and with justfied misgiving. Pontification in these circumstances is especially misplaced, and any semblance of it here is due to the writer's necessity to confine his remarks within limited space and his deficiencies in meeting this necessity more adequately. Anyway, we cannot finally escape the question: Roughly, what considerations are pertinent in the quest to reach standards for legislation concerning obscenity, sound for our society?

Society is composed of individuals who, from the point of view of their inner personality dynamics as much as of their physical habits, are scattered in varying density along the line of a Gaussian curve. If one of the functions of legislation in regard to "obscenity" is to protect people from mental hurt by other people's productions, then is the wind to be tempered for the most shorn of lambs?

It is clear that due to the continued operation of unresolved unconscious infantile complexes, some people are hypersensitive to the most prevalent experiences in life from which they seek to defend themselves vigorously, and they cry out in loud lament if these defenses are one whit disturbed. The artist shares equally with the scientist the task of exploring the truth, among his other functions, and if his efforts are to be thwarted by the pathologically hypersensitive, then most of us would be the losers. Realistic legislation should not seek to protect fully everyone at enormous expense to almost all, especially when protection of this sort can also be stultifying to those who claim it.

Good taste is gradually evolved in a process that Sir Richard Livingstone has described as continued exposure to the first-rate. ${ }^{19}$ The corollary of this, that exposure to the low-rate has depraving effect upon taste, is part of the distilled wisdom of the ages; for example, it is emphasized in The Analects of Confucius. ${ }^{20}$ In the eco-system of the developing individual especially, there is no doubt of the influential effect upon his taste of the group standards.

Broadly stated then, the problem resolves itself into setting a standard which both protects generally against noxious effect upon public taste without pandering to the pathologically hypersensitive and does not threaten frustration of the artist in society. To be sure, there is obviously bound to be considerable difficulty in framing a neat formula to cover these contingencies. In order to scrutinize the problem more effectively, it is proposed here to focus upon an example which has provided considerable difficulty-D. H. Lawrence's famous-or notorious-novel, Lady Chatterley's Lover.

${ }^{10}$ Richard Livingstone, Education for a World Adrift 28-55 (1944).

${ }^{20}$ Throughout The Analects, Confucius shows his belief in the infectious powers of good and bad taste-and, for him, these powers are largely vested at the top of the social trec. Sce THE ANALECTs, or the Conversatrons of Confucius with His Disciples, and Certain Others bk. 3, c. 1, at 16; bk. 12, c. 19, at 123-24; bk. 15, c. 20, at 166; bk. 17, c. 18, at 195; and bk. 19, c. 12, at 209 (W. E. Soothill transl. I937). 
The novel concerns itself with the illicit love affair of a gamekeeper and Lady Chatterley, whose husband is a cripple. There are at least three versions, and in the course of the rewriting, the novel undergoes a strange metamorphosis. The major theme remains in all versions: a triangular situation in which human relationships are imaginatively explored in three connected dimensions-sexual relationship, the closeness or lack of it in human communication, and finally, class barriers as these affect human contact. In the later versions, the emphasis shifts to even greater preoccupation with sex and lessening of attention to other aspects of interpersonal relation. Certainly in the earliest version, there is a warm understanding of humanity, and the characters are depicted in some depth; whereas in the final version, the personalities have somewhat decomposed into pasteboard figures. Appropriate to an ex-miner, the gamekeeper uses language which is frank and pungent in the first version; in the final version, there are also elaborate and cloying purple passages.

From the analytic viewpoint, the theme of the novel has obvious symbolic reference to the triadic experience of early childhood: the forbidden woman is exalted and sensual, the incest barrier is recast with emphasis as both marriage and class barrier, the husband is a castrated being, and sensual victory is afforded the underling. In other words, unresolved and forbidden early incestuous wishes and phantasies are afforded defiant and only moderately indirect expression and elaboration. Concomitantly, modesty of speech is abandoned by the expedient of exposing an upper-class woman to the speech habits of a gamekeeper. Modest women, as Kleinpaul has remarked, have a much greater horror of saying immodest things than of doing them-"they believe that fig-leaves were especially made for the mouth." 21 In this novel, the woman also participates with her lover in frankly sexual conversation.

The novel is brilliantly written; in the first version, at least, characterization is strong, and pari passu with the unfolding of the central conflictual theme and its dénouement, hyprocrisy and humbug in human relations are exposed with much feeling of protest. Lawrence's avowed intention was, after all, to bring deeper insight into human relations and self-recognition to his readers.

Now it seems to me that this is removed from mere pornography. It also seems to me that the use of language cannot be separated from its general content. There is no doubt, however, that such a novel can give offense to many readers, and that some of them would feel disgusted. Such a novel has a particular fascination for the intelligent adolescent and would have value for his understanding of the world as well as providing pleasurable outlet for rebellious feelings against the constrictions and hypocrisies of society. To people of greater experience, it might have also great educational value, causing them to scrutinize more adequately important aspects of interpersonal relationship. All this seems to me to be different from

${ }^{21}$ Rudolf A. R. Kleinpaul, Sprache ohNe Worte 309 (1888), quoted at I Ellis, op. cit. supra note 14 , at 66 . 
the pornography that simply encourages people to luxuriate in morbid, regressive, sexual-sadistic phantasy and cultivates this morbidity in them, tending to arrest their development. The form in pornography is as crude as the content, whereas in this novel, the prose and the structure are those of the fine craftsman.

From such a cursory examination, it would seem that when the content is in doubt, the form should also be considered; and that part of the content cannot be examined separately, but should be considered only in the total configuration. In this case, the novelist is certainly challenging in his treatment of the central theme towards the prevailing social codes and standards of his time. Since those days, however, social mobility has become more pronounced, and there is less hypocrisy about sex, so that his efforts can be seen to have been, in these respects, consistent with the social process. Hindsight, however, is useless for appraisal of a work at the time of its production; it only shows that in numerous instances, the challenges involved to prevailing standards have been healthy and have led to progress.

It is understandable that in these days when pornography can avail itself of all modern techniques in the graphic arts, the cinema, and the sound studio and cast its baleful influence far and wide, that this should lead to increased vigilance on the part of censorship. Increased vigilance should not, however, lead to carelessness in the scrutiny of data nor determine the value-system by means of which the data are finally appraised. In this matter of obscenity and the arts, increased vigilance will only be productive in so far as it leads to more thorough exploration of a problem which hitherto has been left to arbitrary action. 